\title{
Polymorphism of the Human Immunodeficiency Virus Type 1 in Brazil: Genetic Characterization of the nef Gene and Implications for Vaccine Design
}

\author{
ML Guimarães, AS Moreira, MG Morgado+
}

\author{
Departamento de Imunologia, Instituto Oswaldo Cruz-Fiocruz, Av. Brasil 4365, 21045-900 Rio de Janeiro, RJ, Brasil
}

\begin{abstract}
Most of the Brazilian HIV-1 samples have been characterized based on the structural genes (env, gag and pol) and no data concerning the variability of the accessory genes such as nef have been available so far. Considering the role of the nef on virus biology and the inclusion of this region in some HIV/AIDS vaccine products under testing, the purpose of this study was to document the genetic diversity of the nef gene in third-four HIV-1 Brazilian samples previously subtyped based on the env C2-V3 region. Although only few non-subtype B samples have already been analyzed so far, the cytotoxic Tlymphocyte epitopes encoded in this region were relatively conserved among the subtypes, with some amino acid signatures mainly in the subtype $C$ samples. Considering the increasing of the nonB HIV-1 subtypes worldwide, in special the subtype C, more data should be generated concerning the genetic and antigenic variability of these subtypes, as well as the study of the impact of such polymorphism in HIV/AIDS vaccine design and testing.
\end{abstract}

Key words: nef gene - HIV-1 polymorphism - HIV/AIDS vaccine - B cell and CTL nef epitopes

Eighteen years has been past since the identification of the HIV as the etiologic agent of the acquired immunodeficiency syndrome (AIDS) and around 60 millions of individuals have been affected worldwide so far. Although preventive AIDS efforts and anti-retroviral therapies have attenuated the spreading of the epidemic, it is still occurring in a high extent, mainly in developing countries, and the development of preventive vaccines is urgently necessary.

Even though a broad spectrum of information has been accumulated concerning this virus and the immune response against it, effective vaccine formulations are not yet available. The complex biology and genetics of the virus make the development of preventive vaccines an enormous challenge. However it remains the best strategy to control HIV epidemics and is consequently a public healthy priority.

The first HIV/AIDS vaccines candidates tested were based on the envelope glycoproteins gp120 or gp160 of HIV-1. Nevertheless, the response to this type of formulations are type-specific with a relatively short-life, are unable to neutralize typical primary R5 isolate viruses, and inefficient to induce cytotoxic T lymphocyte (CTL) response against the virus (Graham 2000). Thus, the new-

This work was supported by the National Coordination of STD/AIDS/UNDP/World Bank, (UNAIDS), Piaf/Fiocruz/Ministry of Health, Faperj and Brazilian Research Council (CNPq). Fiocruz is an Unaids Collaborative Centre.

${ }^{+}$Corresponding author. Fax: +51-21-2280.1589. E-mail: mmorgado@ioc.fiocruz.br

Received 18 January 2002

Accepted 26 April 2002 est vaccine formulations tried to overcome this problem by the utilization of replicative vectors and the incorporation of other HIV-1 genes, bearing important CTL epitopes, and presenting a more similar structure with the virus, leading to a broader and potentially protective immune response.

The nef gene of the HIV has been the subject of considerable interest since the demonstration that nef-defective viruses cause attenuated disease in both human subjects (Learmont et al. 1992, Huang et al. 1995, Deacon et al. 1995) and rhesus macaque experimental models (Daniel et al. 1992). In addition, animals immunized with a nef-defective virus construction were protected when challenged with a wild-type pathogenic SIV, and the reversion of these mutants to the wild genome results in the regain of high viral load and rapid progression for disease (Kestler et al. 1991, Daniel et al. 1992). Long term non-progression associated with nef-defective HIV-1 samples has been described in both adults and pediatric HIV-infected individuals (Huang et al 1995, Kirchhoff et al.1995, Geffin et al. 2000), although such strict correlation has not been found by others (Michel et al. 1995). Moreover, important $n e f$-associated activities have been described as downregulation of cell surface CD4 and MHC class I molecules (Garcia et al. 1993, Schwartz et al. 1996), modulation/activation of T cell signaling pathways (Baur et al. 1994), and enhancement of infectivity and replication (Miller et al. 1994).

Multiple HLA-restricted CTL epitopes have been identified in the nef gene (Korber et al. 2000), which are described as quite conserved among the HIV-1 subtypes (Artenstein et al. 1996, Jubier-Maurin et al. 1999). Moreover, CTL response against nef epitopes have been postulated to be associated with protection from infection in 
HIV-1 exposed individuals (Langlade-Demoyen et al. 1994).

Due to their high immunogenicity and relative conservation of the CTL epitopes, newly developed vaccines are including the nef gene in their formulations (GaherySegard et al. 2000, Pialoux et al. 2001, Vandepapeliere et al. 2001, Dolin et al. 2001). As those vaccines can be tested in our country, the knowledge about the genetic variability of this region among the prevalent HIV-1 subtypes is of relevance in the potentially vaccine sites. As far as we know, at present there is no sequence information available in the public gene data banks concerning the diversity of the nef gene of Brazilian HIV-1 samples. Thus, the aim of this study is to evaluate the polymorphism of the nef gene among the HIV-1 subtypes prevalent in Brazil.

In order to proceed this study, $34 \mathrm{HIV}-1$ samples from Brazil, previously subtyped by $e n v$-HMA (Brazilian Network of HIV Isolation and Characterization 2000, "unpublished observations"), were selected for this study (7 samples from subtype B, 7 C, 8 F, 2 D, 1 A and 9 corresponding to the B" Brazilian subtype B variant). The nested PCR amplification of the nef region was obtained based on the previously described protocol (Artenstein et al. 1996). DNA sequencing reaction was carried out in a Gene Amp PCR System (Perkin Elmer 9600), using the inner PCR primers set and the Big Dye Terminator kit (Applied Biosystems, Foster City, CA), with minor modifications on the cycling conditions as follows: 25 cycles of $96^{\circ} \mathrm{C} 30^{\prime \prime}, 50^{\circ} \mathrm{C} 20^{\prime \prime}, 60^{\circ} \mathrm{C} 4$ '. Automatic sequencing was performed in an ABI model 377 (Applied Biosystems, Foster City, CA). Sequence edition and translation, as well as deduced amino acid sequence alignments, were performed using sequence analysis software package (GCG 1996). Minor manual adjustments were made to improve the alignments.

Thirty out of 34 selected samples gave positive PCR products with the primers for the nef region. Four samples however, corresponding to the env subtypes C (1), F (2) and B" subtype B variant, were not amplified even after several attempts. Moreover, 3 out of 6 samples subtyped as $\mathrm{C}$ based on the $\mathrm{C} 2-\mathrm{V} 3$ env region, as well as $1 \mathrm{~F}, 1 \mathrm{~B}$ " and $1 \mathrm{~A}$ did not give usable sequences for further analysis, probably due to the polymorphism of the target regions. Indeed, even using the same PCR conditions for DNA sequencing the chromatograms obtained were absolutely unreadable.

Discordant env and nef subtyping was verified for 5 out of 24 samples "unpublished observations", with 3 Fenv/Bnef, 1 B" env/Cnef and 1 Cenv/Bnef. The predicted amino acid sequences of the subtypes B, C, D and F defined based on the nef region were aligned with the HXB2 reference sample (Figure). The inter-subtype polymorphism of domains described as containing crucial biological characteristics as well as of immunologically relevant epitopes was fully analyzed.

The myrislation signal (GGKWSK), a highly antigenic region, is relatively conserved among the four studied subtypes, with substitutions $\mathrm{G} \rightarrow \mathrm{N}$ and $\mathrm{G} \rightarrow \mathrm{S}$ at position 3 for the subtype $C$ samples. The glycine $(G)$ at position 2 , the serine $(\mathrm{S})$ at position 6 and lysine at position 7 were conserved in all samples, as previously described (JubierMaurin et al. 1999).
A region of extensive variability follows the myrislation signal and corresponds to a series of overlapping B cell epitopes recognized by murine monoclonal antibodies to recombinant nef protein (reviewed by Korber et al. 2000). In spite of the high polymorphism of this region, no subtype specific molecular signature could be detected. However, highest pattern of conservation could be observed among the subtype B samples. This same pattern could be verified for the other B cell epitopes described in this fragment (Figure).

The acid region, rich in glutamic acid $(\mathrm{E})$ is quite conserved among the subtypes, with $\mathrm{E}$ to aspartic acid (D) amino acid substitution in some samples and the insertion of glycine and E in samples 95BRRJ012 and 99BRRJ045, respectively of B and D HIV-1 subtypes. The insertion of one glutamine residue was observed for the 3 Brazilian subtype C samples analyzed, as well as for sample 92BR025 also from Southern Brazil (Korber et al. 2000), differing from the subtype $\mathrm{C}$ samples from other countries available in the Los Alamos Data Bank. Indeed, the molecular signature QEEEEE was observed for these samples instead of the QQEEEE detected in the Brazilian subtype C samples.

The proline-rich region $(\mathrm{PXXP})_{3}$ and the potential recognition site for quinase $\mathrm{C}$ phosphorylation (RPMTYK) are highly conserved among the subtypes, and are mapped in a region of $\mathrm{B}$ cell overlapping epitopes. Moreover, the conserved CTL epitope FPVTPQVPLRMTY is also mapped in this region. Substitution of the first treonine (T) to basic amino acids arginine $(\mathrm{R})$ or lysine $(\mathrm{K})$ was observed for the majority of the samples, regardless the HIV-1 subtype, when compared to the HXB2 reference sample.

The second CTL epitope SHFLKEKGGLEGL presents just one conserved amino acid substitution from histidine $(\mathrm{H})$ to phenylalanine $(\mathrm{F})$ in the subtype $\mathrm{C}$ samples. This modification seems to be characteristic of this subtype, as it has also been observed for almost all other subtype C samples already available in the Los Alamos database. Once again, typical substitution from histidine (H) to asparagine $(\mathrm{N})$ in the WIYHTQGYFDPWQNY CTL epitope was observed among the Brazilian subtype $\mathrm{C}$ samples. The presence of this $\mathrm{H} \rightarrow \mathrm{N}$ substitution, although rare among the subtype $\mathrm{B}$ samples, can be frequently observed among other non-B subtypes (Jubier-Maurin et al. 1999, Korber et al. 2000).

Although the amplified fragment does not cover all the extension of the overlapping CTL epitopes mapped in the 3' portion of the nef region (DPEREVLEWRFDSRLA FHHVAREL in the HXB2 reference sample), it is possible to verify the highly polymorphism of this region among the Brazilian HIV-1 samples, independent of the subtype, as can be depicted in the Figure, confirming previous works (Jubier-Maurin et al. 1999, Korber et al. 2000). Conserved $\mathrm{E}^{3} \rightarrow \mathrm{H}, \mathrm{E}^{8} \rightarrow \mathrm{Q}$ and $\mathrm{R}^{14} \rightarrow \mathrm{K}$ were observed among the three subtype $\mathrm{C}$ samples included in the present study.

The blocking of the nef activity at the virus life cycle is an important target for HIV vaccine due, among others, to its role on the down-regulation of CD4 and MHC class I molecules thus limiting the immune system in its capacity of antigen recognition and immune control. The nef CTL 

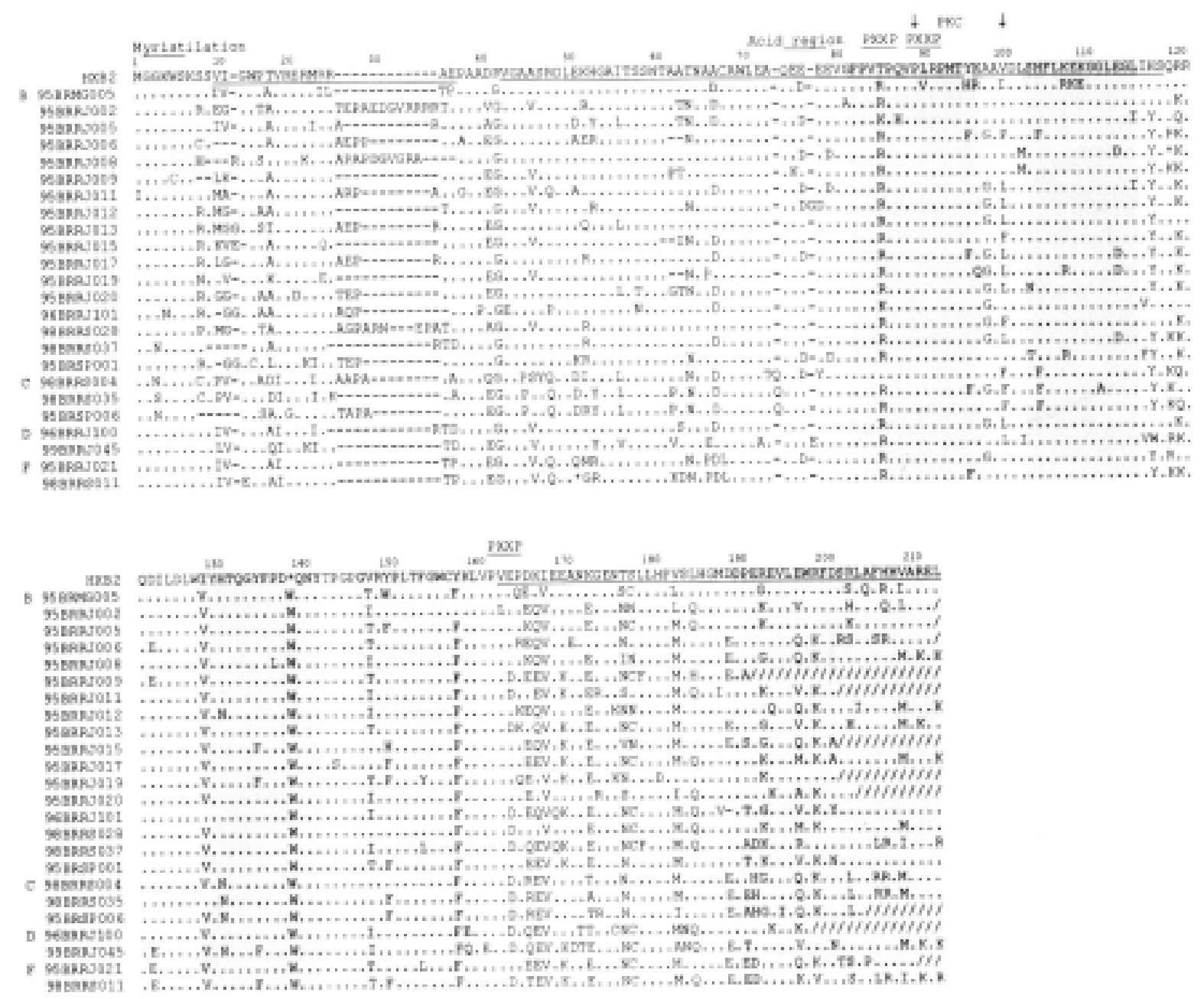

Polymorphism of the nef gene among Brazilian HIV-1 prevalent subtypes: comparison of the deduced amino acid alignments with HXB2 reference sample. The locations of putative functionally important regions are noted. B cell epitopes are underlined; as well as defined CTL epitopes are shaded. Dots represent identity with the HXB2 reference sample; dashes represent gaps. The accession numbers are AY071929 - AY071952.

epitopes have been described as conserved among the HIV-1 subtypes (Jubier-Maurin et al. 1999). Such restricted variability observed among these CTL epitopes probably occur due to their overlapping with crucial regions for the maintenance of some nef biological functions. However, some specific molecular signatures could be observed among the Brazilian subtype $\mathrm{C}$ samples described in the present paper, as well as among those from other countries available in the HIV Molecular Immunology Database 2001 (Korber et al. 2000). Moreover, differences on the magnitude of CTL response to subtype C and subtype B nefbased peptide ELISPOT assay were observed among HIV1 subtype $\mathrm{C}$ infected individuals (Novitsky et al. 2001). Considering the increasing of the non-B HIV-1 subtypes worldwide, in special the subtype $\mathrm{C}$, which corresponds to more than $50 \%$ of the new HIV-1 infections (Esparza \& Bhamarapravati 2000), more data should be generated concerning the genetic and antigenic variability of these sub- types, as well as the study of the impact of such polymorphism in HIV/AIDS vaccine design and testing.

\section{REFERENCES}

Artenstein AW, Hegerich PA, Beyrer C, Rugruengthanakit K, Michael NL, Natprtan C 1996. Sequences and phylogenetic analysis of the nef gene from Thai subjects harboring subtype E HIV-1. AIDS Res Hum Retroviruses 12: 557560.

Baur AS, Sawai ET, Dazin P, Fantl WJ, Chen-Mayer C, Peterlin BM 1994. HIV-1 nef leads to inhibition or activation of T cells depending on its intracellular localization. Immunity 1 : 373-384.

Brazilian Network for the HIV-1 Isolation and Characterization 2000 (Bongertz V, Bou-Habib DC, Brígido LFM, Caseiro M, Couto-Fernandez JC, Ferreira PC, Freitas CO, Galvão-Castro B, Greco D, Guimarães ML, Linhares de Carvalho MI, Morgado MG, Oliveira CAF, Osmanov S, Ramos CA, Rossini M, Sabino E, Tanuri A, Ueda M). HIV1 diversity in Brazil: genetic, biological and immunological 
characterization of HIV-1 strains in three potential HIV vaccine evaluation sites. J AIDS 23: 184-193.

Daniel MD, Kirchhoff F, Czajak SC, Sehgal PK, Desrosiers RC 1992. Protective effects of a live attenuated SIV vaccine with a deletion in the nef gene. Science 258: 1938-1941.

Deacon NJ, Tsykin A, Solomon A, Smith K, Ludford-Menting M, Hooker DJ, McPhee GA, Greenway AL, Ellett A, Chatfield C, Lawson VA, Crowe S, Maerz A, Sonza S, Learmont J, Sullivan JS, Cunningham A, Dwyer D, Dowton D, Mills J 1995. Genomic structure of an attenuated quasispecies of HIV-1 from a blood transfusion donor and recipients. Science 270: 988-991.

Dolin R, El Habib R, the NIAID HIV Vaccine Trials Network (HVTN) 2001. Immunogenicity of Canarypox (ALVAC)HIV-1 Candidate Vaccines in Normal Volunteers. AIDS Vaccine 2001. September 5- 8, Philadelphia, PA, USA.

Gahery-Segard H, Pialoux G, Charmeteau B, Sermet S, Poncelet H, Raux M, Tartar A, Levy JP, Gras-Masse H, Guillet JG 2000. Multiepitopic B- and T-cell responses induced in humans by a human immunodeficiency virus type 1 lipopeptide vaccine. J Virol 74: 1694-703.

Garcia JV, Alfano J, Miller AD 1993. The negative effect of human immunodeficiency virus type 1 nef on cell surface CD4 expression is not species specific and requires the cytoplasmic domain of CD4. J Virol 67: 1511-1516.

Geffin R, Wolf D, Rüdiger M, Hill MD, Stellwag E, Freitag M, Sass G, Scott GB, Baur AS 2000. Functional and structural defects in HIV type 1 nef genes derived from pediatric longterm survivors. AIDS Res Hum Retroviruses 16: 1855-1868.

Graham 2000. Clinical trials of HIV vaccines. In Molecular Immunology Compendium, Los Alamos, NM, p. I20-I38.

Huang Y, Zhang L, Ho DD 1995. Characterization of nef sequences in long-term survivors of human immunodeficiency virus type 1 infection. J Virol 69: 93-100.

Jubier-Maurin V, Saragosti S, Perret J-L, Mpoudi E, SeuWillians E, Mulanga C, Liegeois F, Ekwalanga M, Delaporte E, Peeters M 1999. Genetic characterization of the nef gene from Human Immunodeficiency Virus Type 1 group $M$ strains representing genetic subtypes A,B,C,E,F,G and $\mathrm{H}$. AIDS Res Hum Retroviruses 15: 23-32.

Kestler HW, Ringler DJ, Mori K, Panicali DL, Sehgal PK, Daniel MD, Desrosiers RC 1991. Importance of the nef gene for maintenance of high virus loads and for development of AIDS. Cell 65: 651-662

Kirchhoff F, Greenough TC, Brettler DB, Sullivan JL, Desrosiers
RC 1995. Absence of intact nef sequences in a long-term survivor with nonprogressive HIV-1. N Engl J Med 332: 228-232.

Korber BTM, Brander C, Haynes BF, Koup R, Kuiken C, Moore JP, Walker BD, David Watkins 2000. HIV Molecular Immunology Database, Published by Los Alamos National Laboratory: Theoretical Biology and Biophysics, Los Alamos, NM.

Langlade-Demoyen P, Ngo-Giang-Huong N, Ferchal F, Oksenhendler E 1994. Human immunodeficiency virus (HIV) nef-specific cytotoxic T lymphocytes in non-infected heterosexual contact of HIV-infected patients. J Clin Invest 93: 1293-1297.

Learmont J, Tindall B, Evans L, Cunningham A, Cunningham P, Wells J, Penny R, Kaldor J, Cooper DA 1992. Longterm symptomless HIV-1 infection in recipients of blood products from a single donor. Lancet 340 (8824): 863-867.

Michael NL, Chang G, d'Arcy LA, Tseng CJ, Birx DL, Sheppard HW 1995. Defective accessory genes in a human immunodeficiency virus type 1 infected long term survivor lacking recoverable virus. J Virol 69: 6758-6769.

Miller MD, Warmerdam MT, Gaston I, Greene WC, Feinberg MB 1994. The human immunodeficiency virus-1 nef gene product: a positive factor for viral infection and replication in primary lymphocytes and macrophages. J Exp Med 179: 101-113.

Novitsky V, Rybak N, McLane MF, Gilbert P, Chigwedere P, Klein I, Gaolekwe S, Chang SY, Peter T, Thior I, Ndung'u T, Vannberg F, Foley BT, Marlink R, Lee TH, Essex M 2001. Identification of human immunodeficiency type 1 subtype C gag-, tat-, rev- and nef-specific elispot-based cytotoxic T-lymphocyte responses for AIDS vaccine design. J Virol 75: 9210- 9228.

Pialoux G, Gahery-Segard H, Sermet S, Poncelet H, Fournier S, Gerard L, Tartar A, Gras-Masse H, Levy JP, Guillet JG; ANRS VAC 04 Study Team. Lipopeptides induce cell-mediated anti-HIV immune responses in seronegative volunteers. AIDS 15: 1239-1249.

Schwartz O, Marechal V, Le Gall S, Lemonnier F, Heard JM 1996. Endocytosis of major histocompatibility complex class I molecules is induced by the nef protein. Nat Med 2: 238-342.

Vandepapeliere P, Manson K, Mooij P, Montefiori D, Watkins D, Heeney J, Wyand M, Cohen J, Bruck C, Voss G 2001. AIDS Vaccine 2001. September 5- 8, Philadelphia, PA, USA. 